\title{
Levodopa/carbidopa microtablets in Parkinson's disease: a study of pharmacokinetics and blinded motor assessment
}

\author{
Marina Senek $^{1}$ - Sten-Magnus Aquilonius ${ }^{1}$ - Håkan Askmark ${ }^{1}$ • Filip Bergquist ${ }^{2}$ • \\ Radu Constantinescu ${ }^{3}$ - Anders Ericsson ${ }^{4} \cdot$ Sara Lycke $^{5}$ - Alexander Medvedev ${ }^{6}$. \\ Mevludin Memedi ${ }^{7,8} \cdot$ Fredrik Ohlsson $^{4} \cdot$ Jack Spira $^{9} \cdot$ Jerker Westin $^{7} \cdot$ Dag Nyholm $^{1}$
}

Received: 8 September 2016 / Accepted: 5 January 2017 / Published online: 18 January 2017

(C) The Author(s) 2017. This article is published with open access at Springerlink.com

\begin{abstract}
Background Motor function assessments with rating scales in relation to the pharmacokinetics of levodopa may increase the understanding of how to individualize and fine-tune treatments.

Objectives This study aimed to investigate the pharmacokinetic profiles of levodopa-carbidopa and the motor function following a single-dose microtablet administration in Parkinson's disease.

Methods This was a single-center, open-label, single-dose study in 19 patients experiencing motor fluctuations. Patients received $150 \%$ of their individual levodopa equivalent morning dose in levodopa-carbidopa microtablets. Blood samples were collected at pre-specified time points. Patients
\end{abstract}

Marina Senek

marina.senek@neuro.uu.se

1 Department of Neuroscience, Neurology, Uppsala University, Uppsala, Sweden

2 Department of Pharmacology, University of Gothenburg, Gothenburg, Sweden

3 Department of Clinical Neuroscience, University of Gothenburg, Gothenburg, Sweden

4 Acreo Swedish ICT, Kista, Sweden

5 Cenvigo, Uppsala, Sweden

6 Department of Information Technology, Uppsala University, Uppsala, Sweden

7 Computer Engineering, Dalarna University, Falun, Sweden

8 Informatics, School of Business, Örebro University, Örebro, Sweden

9 Sensidose AB, Sollentuna, Sweden were video recorded and motor function was assessed with six UPDRS part III motor items, dyskinesia score, and the treatment response scale (TRS), rated by three blinded movement disorder specialists.

Results $\mathrm{AUC}_{0-4 / \mathrm{dose}}$ and $C_{\max / \mathrm{dose}}$ for levodopa was found to be higher in Parkinson's disease patients compared with healthy subjects from a previous study, $(p=0.0008$ and $p=0.026$, respectively). The mean time to maximum improvement in sum of six UPDRS items score was $78 \mathrm{~min}$ $( \pm 59)(n=16)$, and the mean time to TRS score maximum effect was $54 \min ( \pm 51)(n=15)$. Mean time to onset of dyskinesia was $41 \mathrm{~min}( \pm 38)(n=13)$.

Conclusions In the PD population, following levodopa/ carbidopa microtablet administration in fasting state, the $\mathrm{C}_{\max }$ and $\mathrm{AUC}_{0-4 / \text { dose }}$ were found to be higher compared with results from a previous study in young, healthy subjects. A large between subject variability in response and duration of effect was observed, highlighting the importance of a continuous and individual assessment of motor function in order to optimize treatment effect.

Keywords Parkinson's disease · Pharmacokinetics · Pharmacodynamics $\cdot$ Levodopa

\section{Introduction}

Levodopa is currently the most effective symptomatic treatment for PD, and it remains effective throughout the entire course of the disease. However, as the disease progresses, the therapeutic window narrows and along with the short half-life of levodopa, the symptoms become increasingly difficult to treat [1]. The motor fluctuations that may develop within months to years after levodopa treatment start [2], 
i.e., off (episodes with Parkinsonism), on (near normal motor function), and on with peak-dose dyskinesia (on with involuntary movement) [3], can in advanced PD patients be associated to the oscillating levodopa plasma concentration [4]. One of the core elements of dose titration and continued treatment is evaluation of patient mobility, and how it changes over time. Today, it largely relies on the patient's subjective assessment of symptoms and clinicians' assessment of patient status during the brief moment they meet. An increased understanding of assessments with rating scales in relation to the pharmacokinetics of levodopa may increase the understanding of how to individualize and fine-tune treatments.

Jejunal infusion of levodopa/carbidopa gel, allowing finetuning of doses [5] which reduces motor fluctuations in patients with advanced PD [6], has demonstrated the importance of individualized doses and a stable plasma concentration [7]. In theory, oral levodopa administration could have similar effects, up to a certain degree, when administered more frequently, but it is difficult to adhere to [8]. A dose dispenser with alarm and memory function, for dispersible low-dose levodopa microtablets (levodopa [5 $\mathrm{mg}$ ] and carbidopa $[1.25 \mathrm{mg}]$ ), has been developed (Flexilev ${ }^{\circledR}$ and MyFid $\AA$, Sensidose AB, Sollentuna, Sweden) to facilitate adherence and fine-tuning of oral dosing [9]. The dispenser keeps track of doses and pre-programmed time points for administration and the low-dose microtablets allow a fine-tuned dosing in accordance with patients' needs [10]. The treatment was used in Sweden on licensed prescription between 2013 and 2014. From June 2016, it was made available for prescription to all patients with advanced PD. Recently, it was also approved (2016) by EMA in 13 further EU countries following the mutual recognition procedure.

The aim was to investigate the pharmacokinetic profiles of levodopa and carbidopa, and to assess motor function following a single-dose microtablet administration in Parkinson's disease patients.

\section{Methods}

Study protocol, approvals, registrations, and patient consents The Uppsala Ethical Review Board approved this study and written informed consent was obtained from all participants. The study was conducted in Sweden in accordance with the ethical principles of the Declaration of Helsinki as adopted by the World Medical Association.

\section{Inclusion criteria}

Patients diagnosed with idiopathic PD at the Uppsala University Hospital's neurology clinic were screened for eligibility. Eligible patients for this study were currently treated with levodopa and experiencing motor complications, i.e., motor fluctuations, verified with wearing-off questionnaire and/or dyskinesia. Patients were excluded if they had ongoing deep brain stimulation treatment, were pregnant, breast-feeding, had any contraindication for the use of levodopa or carbidopa, or had other reasons for exclusion at the discretion of the investigator.

\section{Study design and medication}

This single center, open-label, single-dose study, involving levodopa/carbidopa microtablets, was conducted at CTC (Clinical Trials Consultants AB) Center at the University Hospital in Uppsala, Sweden, between May and August 2015.

The dose administered was $150 \%$ of the calculated levodopa/carbidopa equivalents, a suprathreshold challenge dose as in a previous study [11], to follow the patient's transition from off-state, to normal mobility and/or evoked dyskinesia, and the regression back. A patient's dose was calculated from the usual morning dose of levodopa and other anti-PD drugs, because no other anti-PD drug were allowed on the day of the study. On the morning of the study, the patients received a fasting dose of their usual morning dose in levodopa/ carbidopa calculated equivalents, after an 8-h washout. The microtablets were dispersed in a glass of water, $100 \mathrm{~mL}$. The patients drank the full volume of dispersed drug while seated.

No other anti-PD drugs were allowed during the pharmacokinetic study day. The patients were allowed to discontinue the further testing prior to the planned protocol stopping time if they could no longer remain without medication.

The levodopa/carbidopa equivalent dose conversion was based on a study and a systematic review $[12,13]$ comparing the pharmacokinetics and effect between levodopa/carbidopa, levodopa/benserazide, and other anti-Parkinson drug formulations.

The conversion factor was for levodopa/benserazide: milligram of levodopa $\times 1.2$ and for a formulation with entacapone: milligram of levodopa $\times 1.33$. For formulations without levodopa, the conversion factor was for pramipexole: milligram of pramipexole (as salt) $\times 12.5$; for ropinirole: milligram of ropinirole $\times 2.5$; for rasagiline: milligram of rasagiline $\times 8.33$; for apomorphine: milligram of apomorphine $\times 10$; and for amantadine: milligram of amantadine $\times 1$. The prolonged release formulation conversion factors were adjusted for three times daily levodopa administration.

\section{Pharmacokinetic sampling}

Up to 15 samples were collected from each patient, at prespecified time points; one blood sample prior to dosing, one in conjunction with study dose administration at time 0 , and thereafter at 15, 30, 45, 60, 80,100, 120, 150, 180, 210, 240, 300 , and $360 \mathrm{~min}$ after dose administration. 


\section{Pharmacodynamic measurements}

During the inclusion visit, the patients were asked to answer a part of the Unified Parkinson's Disease Rating Scale (UPDRS) part IV, questions 32 to 42, and the 9-item wearing-off questionnaire [14].

During the study, the motor function assessment was conducted in repeated test cycles: once before the study dose administration and then repeatedly every 20 min until $111 \mathrm{~min}$, and subsequently every $30 \mathrm{~min}$ until $321 \mathrm{~min}$ (time of the last test) or until the patient could no longer remain without medication.

The patients were asked to sit on a chair with no armrests. The video recording was started and the patient was instructed to perform the UPDRS-III items in accordance with previous studies [15] and the UPDRS [13]; (1) rapid alternating movements of hands, while seated, one arm at a time, (2) sit, look into the camera, (3) read a text developed by speech therapists for $1 \mathrm{~min}$ [16], (4) tap the index finger on the thumb ten times as quickly as possible with the largest amplitude possible, one hand at a time, (5) tap the heel on the ground in rapid succession picking up the entire leg ten times as high and as fast as possible, one heel at a time, and then 6) rise from the chair with arms folded across the chest, let the arms down, walk a few meters, turn, walk back, and sit down.

\section{Video rating}

A computer program was used to randomize the video sequences to ensure that the video recordings were presented in a randomized order to the three movement disorder specialists, here abbreviated as SMA, HA, and RC, to ensure that the rating was blinded with respect to time from dose administration. The six UPDRS items finger tapping (item 23), rapid alternating movements of hands (item 25), tapping the heel (item 26, only rated by two of the raters), arising from chair (item 27), gait (item 29), and bradykinesia (item 31) were rated according to the definitions of the motor examination part of the UPDRS, with a score of 0 to 4 , per time point and item. These six items were summed up to a UPDRS item score.

The raters also noted if the patient had choreatic and/or dystonic dyskinesia and rated severity from 0 to 4 . The patients overall mobility was also rated, according to the Treatment Response Scale (TRS), a seven step scale ranging from -3 (severe parkinsonism) to 0 (normal mobility) to +3 (severe choreatic dyskinesia) [15]. In the case of mixed patterns, the instructions were to rate according to the dominating movement pattern, with the walking ability weighted as more important.

\section{Safety assessment}

Patients were monitored for adverse events throughout the study.

\section{Statistical analysis}

The pharmacokinetic and statistical analyses were performed with the software R 3.2.2 [17, 18]. The blood samples that were not drawn on the exact time point were approximated to the pre-specified times for the statistical analysis. Each patient was rated regarding six UPDRS items, dyskinesia scores, and TRS score by each of the three raters for all time points. The raters' median scores for the six UPDRS item scores were summed up per time point into a total value.

The calculated pharmacokinetic parameters were baselineand dose-adjusted (to $100 \mathrm{mg}$ for levodopa and $25 \mathrm{mg}$ for carbidopa) maximum concentration $\left(C_{\max / \text { dose }}\right)$ and area under the plasma concentration time curve $\left(\mathrm{AUC}_{0-4 / \text { dose }}\right)$ of levodopa and carbidopa. The measured concentration at time 0 was subtracted from the rest of the measurements that were then divided with the individual administered dose of each compound and multiplied with 100 (levodopa) or 25 (carbidopa). Patients that remained without additional medication for at least $4 \mathrm{~h}$ were included in the analysis of $\mathrm{AUC}_{0-4 / \text { dose. }}$. At least three descending measurements after the peak were required for the calculation of $t_{1 / 2}$. All measurements available were included in the calculation of $t_{1 / 2}$. The mean time to maximum concentration $\left(T_{\max }\right)$ was calculated for all patients. Levodopa and carbidopa $\mathrm{AUC}_{0-4 / \text { dose }}, C_{\max / \text { dose }}$, and $t_{1 / 2}$ were statistically compared with previously reported values in healthy subjects [12]. The statistical analysis of $\mathrm{AUC}_{0-4 / \text { dose }}, C_{\max / \text { dose }}$, and $t_{1 / 2}$ was conducted with the Welch two-sample $t$ test, due to unequal variances and number of individuals. The statistical comparison of $T_{\max }$ was carried out with a Wilcoxon rank sum test.

\section{Bioanalysis of analytes}

The blood samples were collected in EDTA tubes, stored on ice, and centrifuged (20 min, Sorvall SL50T, $3900 \mathrm{rpm}$ ) within $1 \mathrm{~h}$. The plasma was stored frozen at $-80^{\circ} \mathrm{C}$ until analysis (within 6 months). All samples were analyzed at The Department of Pharmacology, University of Gothenburg, Sweden.

After thawing, $0.5 \mathrm{~mL}$ of plasma was mixed with 4dihydroxybenzylamine $(1 \mathrm{mg} / \mathrm{ml})$ and added to $500 \mu \mathrm{L}$ trichloroacetic acid to precipitate proteins. After vortex for $5 \mathrm{~min}$, the samples were centrifuged at $6500 \mathrm{rpm}$ for $10 \mathrm{~min}$ at +4 degrees, 5000 RCF. Fifty microliters of supernatant was transferred to a HPLC vial and 3-5 $\mu 1$ was injected on HPLCED system.

The HPLC system consisted of a pump (Dionex Ultimate 3000 pump) equipped with a $\mathrm{C}_{18}$ reverse phase, $2.0 \mathrm{~mm} \times 200 \mathrm{~mm}$ column (Onyx). The system was connected to an auto sampler equipped with a tray cooling kept at $+4{ }^{\circ} \mathrm{C}$. The detection device was an amperometric detector (Waters 450). The mobile phase consisted of $50 \mathrm{mmol} / \mathrm{L}$ phosphate buffer, pH 2.88 with EDTA $100 \mathrm{mg} / \mathrm{L}$, methanol 4.0\%, acetonitrile $1.5 \%$, and 1 -octanesulphonic acid $100 \mathrm{mg} / \mathrm{L}$. The 
method was validated in agreement with the ICH Validation of Analytical Procedures Q2, R1, step 4 version $(\mathrm{ICH}=$ International Conference on Harmonization of technical requirements for registration of pharmaceuticals for human use).

Plasma samples were assayed for levels of levodopa and carbidopa. The correlation coefficient $(r)$ for linearity determined by the method of least squares was more than 0.995 and the limits of quantification (LOQ) were 10 and $20 \mathrm{ng} / \mathrm{mL}$ for levodopa and carbidopa, respectively.

\section{Results}

\section{Study population}

Nineteen patients, 14 male and 5 female, experiencing wearing-off symptoms and/or dyskinesia, were enrolled (Table 1).
The converted anti-PD drugs were levodopa/benserazide $(n=15)$, levodopa/carbidopa $(n=4)$ immediate release, entacapone $(n=3)$, pramipexole $(n=4$, one with prolonged release formulation), ropinirole prolonged release $(n=3)$, ropinirole immediate release $(n=1)$, rasagiline $(n=4)$, apomorphine $(n=2)$, and amantadine $(n=1)$.

Ten patients remained without additional medication until the last motor function test (321 min), and five patients did not take any additional medication containing levodopa until the last blood sample, at $360 \mathrm{~min}$, was drawn.

\section{Pharmacokinetics of levodopa and carbidopa}

All patients had some detectible levodopa at time 0 ; therefore, baseline- and dose-adjusted $C_{\max }\left(C_{\max / \text { dose }}\right)$ and $\mathrm{AUC}\left(\mathrm{AUC}_{0}\right.$ 4/dose) were calculated (Table 2). One patient had two blood samples drawn 5 and 6 min later than pre-specified time. The time points were approximated to the pre-specified time points.

Table 1 Patient characteristics, $n=19$

\begin{tabular}{|c|c|c|c|c|c|c|c|c|c|c|c|c|c|}
\hline ID & Sex & Age & BMI & $\begin{array}{l}\text { Symptom } \\
\text { onset } \\
\text { (years) }\end{array}$ & $\begin{array}{l}\text { Diagnosis } \\
\text { (years) }\end{array}$ & $\begin{array}{l}\text { Start } \\
\text { LD } \\
\text { (years) }\end{array}$ & $\begin{array}{l}\text { Hoehn } \\
\text { \& Yahr }\end{array}$ & $\begin{array}{l}\text { UPDRS } \\
\text { IV }\end{array}$ & $\begin{array}{l}\text { Wearing } \\
\text { off }^{\mathrm{b}, \mathrm{c}} \text { (yes/ } \\
\text { no) }\end{array}$ & $\begin{array}{l}\text { Dyskinesiab, } \\
\text { d (yes/no) }\end{array}$ & $\begin{array}{l}\text { Study dose } \\
\text { LD/CD (mg) }\end{array}$ & $\begin{array}{l}\text { Last } \\
\text { blood } \\
\text { sample }\end{array}$ & $\begin{array}{l}\text { Last } \\
\text { motor } \\
\text { function } \\
\text { test }\end{array}$ \\
\hline $\mathrm{A}^{\mathrm{a}}$ & Male & 69 & 22.8 & 11 & 10 & 10 & 4 & 8 & Yes & Yes & $300 / 75$ & 300 & 291 \\
\hline B & Female & 70 & 22.4 & 11 & 10 & 10 & 4 & 11 & Yes & Yes & $220 / 55$ & 300 & 321 \\
\hline $\mathrm{C}$ & Male & 64 & 26.5 & 10 & 6 & 6 & 3 & 14 & Yes & Yes & $345 / 86.25$ & 180 & 171 \\
\hline $\mathrm{D}^{\mathrm{a}}$ & Male & 66 & 25.5 & 17 & 15 & 14 & 3 & 4 & Yes & Yes & $410 / 102.5$ & 240 & 261 \\
\hline $\mathrm{E}^{\mathrm{a}}$ & Male & 61 & 22.3 & 13 & 11 & 11 & 3 & 5 & Yes & Yes & $360 / 90$ & 240 & 261 \\
\hline $\mathrm{F}^{\mathrm{a}}$ & Female & 82 & 21.5 & 12 & 9 & 9 & 3 & 7 & Yes & Yes & $360 / 90$ & 240 & 261 \\
\hline G & Female & 73 & 25.6 & 17 & 15 & 13 & 3 & 9 & Yes & Yes & $155 / 38.75$ & 210 & 201 \\
\hline $\mathrm{H}^{\mathrm{a}}$ & Male & 79 & 27.7 & 6 & 4 & 4 & 3 & 4 & Yes & Yes & $370 / 92.5$ & 240 & 261 \\
\hline $\mathrm{I}^{\mathrm{a}}$ & Female & 76 & 24.2 & 23 & 12 & 12 & 3 & 7 & Yes & Yes & $250 / 62.5$ & 300 & 321 \\
\hline $\mathrm{J}^{\mathrm{a}}$ & Male & 61 & 24.5 & 7 & 4 & 4 & 2 & 3 & Yes & No & $270 / 67.5$ & 300 & 321 \\
\hline $\mathrm{K}^{\mathrm{a}}$ & Male & 80 & 24.7 & 7 & 5 & 5 & 2 & 2 & No & Yes & $360 / 90$ & 360 & 321 \\
\hline $\mathrm{L}^{\mathrm{a}}$ & Male & 74 & 23.4 & 8 & 8 & 8 & 4 & 4 & Yes & No & $110 / 27.5$ & 360 & 321 \\
\hline $\mathrm{M}^{\mathrm{a}}$ & Male & 74 & 30.0 & 6 & 5 & 5 & 3 & 2 & Yes & No & $250 / 62.5$ & 300 & 321 \\
\hline $\mathrm{N}$ & Male & 80 & 22.5 & 35 & 33 & 33 & 5 & 9 & Yes & Yes & $250 / 62.5$ & 180 & 171 \\
\hline $\mathrm{O}^{\mathrm{a}}$ & Male & 73 & 22.2 & 7 & 6 & 6 & 2 & 5 & Yes & No & $180 / 45$ & 360 & 321 \\
\hline $\mathrm{P}^{\mathrm{a}}$ & Male & 68 & 28.3 & 9 & 9 & 9 & 3 & 9 & Yes & Yes & $295 / 73.75$ & 360 & 321 \\
\hline Q & Male & 69 & 20.0 & 17 & 13 & 13 & 5 & 7 & Yes & Yes & $365 / 91.25$ & 300 & 231 \\
\hline $\mathrm{R}^{\mathrm{a}}$ & Female & 65 & 26.3 & 4 & 2 & 2 & 3 & 3 & Yes & No & $180 / 45$ & 300 & 321 \\
\hline $\mathrm{S}^{\mathrm{a}}$ & Male & 72 & 28.7 & 12 & 7 & 7 & 2 & 5 & Yes & No & $195 / 48.75$ & 360 & 321 \\
\hline MEAN & $14 / 5$ & 71.4 & 24.7 & 12.2 & 9.7 & 9.5 & - & - & - & - & $275 / 68.75$ & 285.8 & 280.0 \\
\hline SD & - & 6.3 & 2.7 & 7.3 & 6.8 & 6.5 & - & - & - & - & $86.3 / 21.6$ & 58.7 & 51.7 \\
\hline
\end{tabular}

$L D$ levodopa, $C D$ carbidopa

${ }^{\text {a }}$ Included in the PK analyses

${ }^{\mathrm{b}}$ Reported at inclusion

${ }^{\mathrm{c}}$ Based on wearing-off questionnaire

${ }^{\mathrm{d}}$ Based on UPDRS IV

${ }^{\mathrm{e}}$ Levodopa/carbidopa equivalents based on individual morning dose 
Table 2 Pharmacokinetic parameters of levodopa and carbidopa

\begin{tabular}{|c|c|c|c|c|c|c|c|c|c|c|c|c|}
\hline & \multicolumn{6}{|c|}{ Levodopa } & \multicolumn{6}{|c|}{ Carbidopa } \\
\hline & $\mathrm{N}$ & Mean & $\mathrm{SD}$ & Min & Median & Max & $\mathrm{N}$ & Mean & SD & Min & Median & $\operatorname{Max}$ \\
\hline \multicolumn{13}{|l|}{ Patients } \\
\hline$C_{\max / \text { dose }}(\mu \mathrm{g} / \mathrm{mL})^{\mathrm{a}}$ & 19 & $1.17^{\dagger \dagger}$ & 0.43 & 0.31 & 1.16 & 1.96 & 19 & $0.09^{\dagger}$ & 0.03 & 0.03 & 0.09 & 0.14 \\
\hline$T_{\max }(\min )$ & 19 & 32 & 23 & 15 & $30^{\dagger}$ & 100 & 19 & 134 & 47 & 80 & $120^{\dagger}$ & 240 \\
\hline AUC $_{0-4 h / d o s e}{ }^{\text {a, b }}\left(\min ^{\mathrm{c}} \mu \mathrm{g} / \mathrm{mL} / \mathrm{mg}\right)$ & 14 & $1.15^{\dagger \dagger}$ & 0.31 & 0.38 & 1.21 & 1.74 & 14 & $0.67^{\dagger}$ & 0.26 & 0.23 & 0.68 & 1.14 \\
\hline$t_{1 / 2}^{\mathrm{d}}(\min )$ & 14 & $106^{\dagger}$ & 16 & 85 & 104 & 144 & $13^{\mathrm{e}}$ & $171^{\dagger \dagger}$ & 37 & 117 & 173 & 248 \\
\hline \multicolumn{13}{|l|}{ Healthy volunteers [11] } \\
\hline$C_{\max }(\mu \mathrm{g} / \mathrm{mL})$ & 18 & 0.90 & 0.25 & 0.51 & 0.88 & 1.38 & 18 & 0.09 & 0.05 & 0.03 & 0.09 & 0.21 \\
\hline$T_{\max }(\min )$ & 18 & 37 & 23 & 20 & 35 & 120 & 18 & 109 & 48 & 40 & 100 & 180 \\
\hline 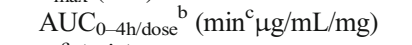 & 18 & 0.77 & 0.17 & 0.53 & 0.75 & 1.13 & 18 & 0.58 & 0.32 & 0.17 & 0.52 & 1.44 \\
\hline$t_{1 / 2} \mathrm{c}(\mathrm{min})$ & 18 & 91 & 34 & 45 & 85 & 198 & 18 & 125 & 72 & 56 & 101 & 315 \\
\hline
\end{tabular}

${ }^{\mathrm{a}}$ Baseline and dose adjusted

${ }^{\mathrm{b}}$ Time points 0-240 $\min (0-4 \mathrm{~h})$. Five patients were excluded because they did not have data until $240 \mathrm{~min}$

${ }^{c}$ Reused with permission from the Wolters Kluwer Health, Inc. (Clinical Neuropharmacology)

${ }^{\mathrm{d}}$ At least three descending concentration time points were used for the calculation of $t^{1 / 2}$. All time points included

${ }^{\mathrm{e}}$ Patient $\mathrm{F}$ did not have descending time points at end of trial

${ }^{\dagger}$ not found to be significant, compared with healthy volunteers from previous study [12]

${ }^{\dagger} p<0.05$, compared with healthy volunteers from previous study [12]

Mean baseline-adjusted $C_{\max / \text { dose }}$ and $\mathrm{AUC}_{0-4 / \text { dose }}$ for levodopa was higher in patients compared with healthy levodopa-naive subjects from a previous study [12] $(p=0.026,[0.270,95 \%$ CI: $0.0350-0.505]$ and $p=0.0008$, [0.378, 95\% CI: $0.179-0.576]$, respectively) (Fig. 1). $T_{\max }$ for levodopa and carbidopa did not differ between the patients and the healthy volunteers; however, the times of blood-sampling slightly differed between the comparative study and this study during the first hour. Sampling time points were same in both studies between hour 1 and 3. Carbidopa half-life for patient was found to be longer compared to healthy subjects $(p=0.029,[46.0,95 \%$ CI: $5.23-86.7])$.

\section{Pharmacodynamics represented by six UPDRS items, dyskinesia, and TRS scores}

The mean $( \pm \mathrm{SD})$ sum of the six UPDRS item score, dyskinesia, and TRS scores per time point are shown in Fig. 2. The mean UPDRS item score at dose intake was 7.4, and the mean TRS score was -1.4. The dyskinesia score was 0 for all patients at time 0 . Individual results are presented in Table 3.

The mean $( \pm \mathrm{SD})$ time to maximum sum of UPDRS item improvement was $79 \min ( \pm 60)(n=16)$, excluding the three patients who did not show any improvement, or worsened.
Fig. 1 Baseline- and doseadjusted levodopa (to $100 \mathrm{mg}$ ) and carbidopa (to $25 \mathrm{mg}$ ) plasma concentration profiles $($ mean $\pm \mathrm{SD})$ for patients over time for patients and non-adjusted for healthy subjects [12]. Pharmacokinetic mean $( \pm \mathrm{SD})$ profiles of levodopa and carbidopa in plasma $(\mu \mathrm{g} / \mathrm{mL})$, Patients profiles are baseline- and dose-adjusted to $100 \mathrm{mg}$ levodopa and $25 \mathrm{mg}$ carbidopa over time. Filled triangles: Patients (levodopa, $n=14$; carbidopa, $n=13$ ), empty circles: healthy subjects $(n=18)$. Data from healthy subjects reused with permission from the Wolters Kluwer Health, Inc. (Clinical Neuropharmacology)
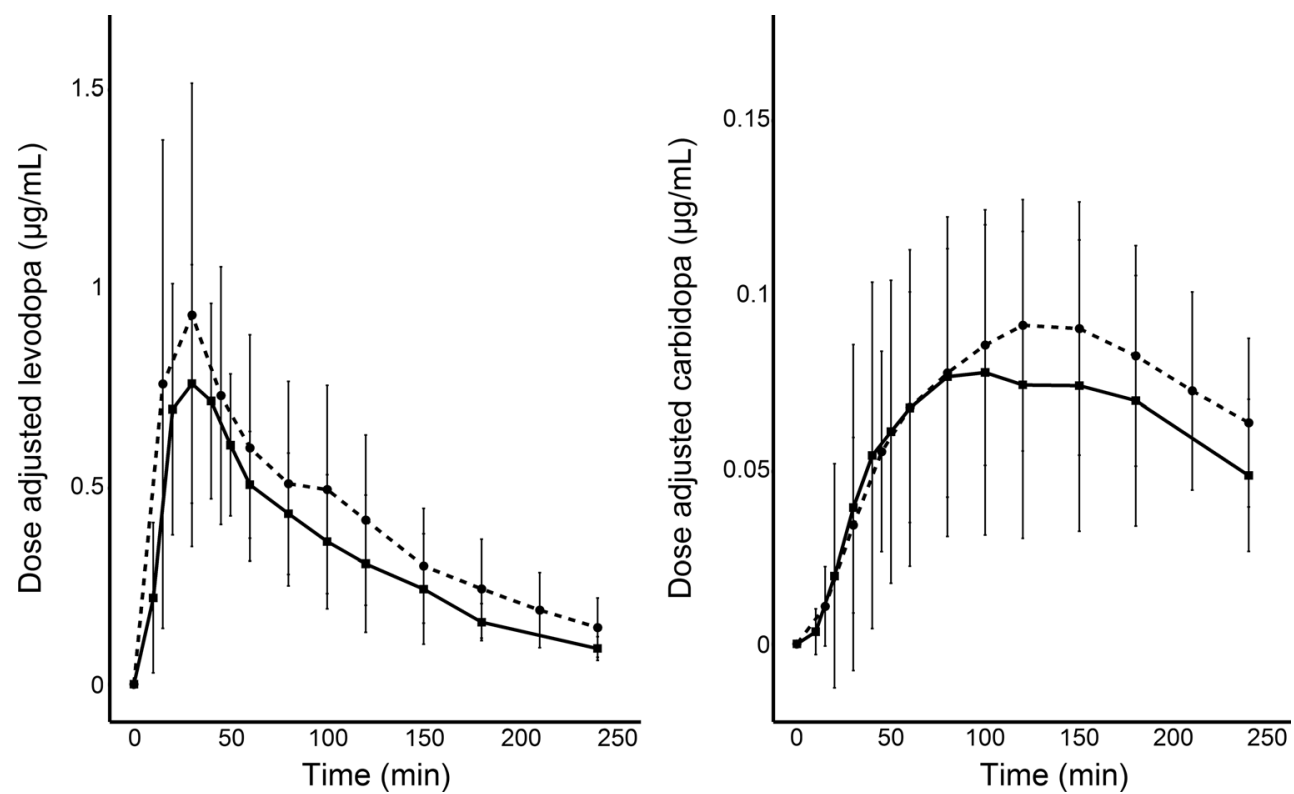



Fig. 2 Mean $( \pm$ SD) UPDRS item score, dyskinesia, and TRS scores $(n=19)$. Motor function assessed over time, after intake of a suprathreshold individual dose of levodopa/carbidopa microtablets

$C_{\max / \text { dose }}$ was $1.14 \mu \mathrm{g} / \mathrm{mL}( \pm 0.46)$ and $T_{\max }$ was $34 \min ( \pm 24)$ for the 16 patients. The mean duration of effect was $154 \mathrm{~min}$ $( \pm 73)(n=14)$.

The median cutoff value for onset of choreatic dyskinesia was set to 1 , meaning that at least two of the raters rated the patient as dyskinetic with at least a score of 1 . Six patients did not show any sign of dyskinesia throughout the study (Table 3, Fig. 2). Mean time to onset of dyskinesia was $42 \min ( \pm 39)(n=13)$. The mean time to maximum dyskinesia score was $56 \min ( \pm 37)(n=13)$.
The mean time to TRS score effect maximum was 54 min $( \pm 52)(n=15)$, excluding patients who did not show any improvement, or worsened. $C_{\max / \text { dose }}$ was $1.15 \mu \mathrm{g} / \mathrm{mL}$ $( \pm 0.47)$ and $T_{\max }$ was $35 \mathrm{~min}( \pm 24)$ for the 15 patients. The mean duration of effect, calculated for the patients that returned to a score of less than 0 on the TRS, was $180 \mathrm{~min}$ $( \pm 53)(n=8)$.

\section{Adverse events}

One patient vomited $25 \mathrm{~min}$ after dose administration and one patient felt nauseous after $40 \mathrm{~min}$. Two patients fell once during the walking test, at $40 \mathrm{~min}$, and at $60 \mathrm{~min}$ after dose administration. There were no injuries and the patients did not discontinue the study. No serious or severe AEs were reported during the study or led to discontinuation or change in therapy.

\section{Discussion}

This is the first pharmacokinetic study where PD patients received levodopa/carbidopa microtablets. The aim was to characterize the pharmacokinetics of levodopa/carbidopa microtablets and to investigate the motor response, during the transition from off-state, to normal mobility and/or dyskinesia and the regression back, in patients with advanced PD following a 50\% increased levodopa equivalent morning dose. Since the main inclusion criteria were wearing off symptoms and/ or dyskinesia, the group became heterogeneous regarding years since symptom onset, diagnosis, and start of levodopa treatment. Due to PD severity, not all patients could remain without additional medication for $6 \mathrm{~h}$ from study start. The individual morning doses administered were in some patients very high, ranging from 110/27.5 to $410 / 102.5 \mathrm{mg}$ of levodopa and carbidopa, respectively. The range demonstrates the large inter-individual variability in dose requirement that exists among patients [19]. Doses administered were 50\% higher than usual, and the equivalence algorithm, which is an approximation to the levodopa equivalent doses, may have exaggerated the doses further causing more dyskinesia than would be observed with the patients optimal doses. Four patients had rasagiline, a MAO-B inhibitor. The study design with only an overnight washout means that the rasagiline effect was not washed out [20]. This could have influenced the motor function by perhaps increasing the peak dose effect and delaying the time to wearing off in the patients.

The pharmacokinetics for the levodopa/carbidopa microtablets in patients were compared to previous reports in healthy subjects [12]. The baseline-adjusted levodopa 
Table 3 Time points (minutes) for improvement and deterioration according to blinded ratings of UPDRS item score, dyskinesia and TRS score for each patient

\begin{tabular}{|c|c|c|c|c|c|c|}
\hline ID & $\begin{array}{l}\text { UPDRS III } \\
\text { improvement } \\
\text { of } \geq 2^{\mathrm{a}} \text { points }\end{array}$ & $\begin{array}{l}\text { UPDRS III } \\
\text { return to } \\
\text { baseline }^{\mathrm{a}}\end{array}$ & $\begin{array}{l}\text { TRS } \\
\text { score } \geq 0\end{array}$ & $\begin{array}{l}\text { TRS } \\
\text { score }<0\end{array}$ & $\begin{array}{l}\text { Choreatic } \\
\text { dyskinesia } \\
\text { score } \geq 1\end{array}$ & $\begin{array}{l}\text { Choreatic } \\
\text { dyskinesia } \\
\text { score }<1\end{array}$ \\
\hline A & 41 & 201 & 41 & 201 & 41 & 201 \\
\hline B & 21 & 171 & 21 & 171 & 21 & 171 \\
\hline $\mathrm{C}$ & 21 & - & 21 & - & 21 & - \\
\hline $\mathrm{D}$ & 21 & 261 & 21 & 261 & 21 & 261 \\
\hline $\mathrm{E}$ & 21 & 171 & 21 & 171 & 21 & 171 \\
\hline F & 21 & 201 & 21 & 261 & 21 & 261 \\
\hline G & 41 & 111 & 21 & 111 & - & - \\
\hline $\mathrm{H}$ & 81 & 171 & - & - & - & - \\
\hline I & - & - & 21 & - & 111 & - \\
\hline $\mathrm{J}$ & 201 & 291 & - & - & 141 & 291 \\
\hline K & - & - & - & - & 21 & - \\
\hline $\mathrm{L}$ & 61 & 81 & - & - & - & - \\
\hline M & 141 & 261 & - & - & - & - \\
\hline $\mathrm{N}$ & - & - & - & - & 21 & - \\
\hline $\mathrm{O}$ & 21 & 201 & - & - & - & - \\
\hline $\mathrm{P}$ & 21 & 291 & 41 & 291 & 21 & 291 \\
\hline Q & 41 & 201 & 41 & 201 & 41 & 201 \\
\hline $\mathrm{R}$ & $21^{\mathrm{b}}$ & $291^{\mathrm{b}}$ & 21 & - & 41 & 261 \\
\hline $\mathrm{S}$ & - & - & - & - & - & - \\
\hline Median $^{c}$ & 21 & 201 & 21 & 201 & 21 & 261 \\
\hline $\mathrm{n}$ & 15 & 14 & 11 & 8 & 13 & 9 \\
\hline
\end{tabular}

UPDRS part III; six items rated from 0 to 4 ; choreatic dyskinesia, rated from 0 to 4

TRS treatment response scale rating from -3 to +3

${ }^{a}$ At most 1.5 points improvement from baseline or worsening (for patients who had an improvement of $\geq 2$ points)

${ }^{\mathrm{b}}$ Within this range there were two occasions of temporary improvement/deterioration from baseline

${ }^{\mathrm{c}}$ For patients that improved and deteriorated according to the cut off values
$\mathrm{AUC}_{0-4 / \text { dose }}$ and $C_{\text {max/dose }}$ was found to be higher in patients compared with healthy volunteers, an effect that has been previously seen and suggested to be related to long-term levodopa therapy and age [21-24]. The baseline and dose adjustments may however have contributed to a bias, resulting in an underestimation of the $\mathrm{AUC}_{0-4 / \text { dose }}$ and $C_{\max / \mathrm{dose}}$. The patients that were included in the calculation of half-life had measurements for at least $4 \mathrm{~h}$. The time may not be long enough for calculation of carbidopa half-life. Carbidopa half-life was found to be longer in patients compared with healthy subjects.

The complexity behind motor response to different levodopa doses and the individual variability is well known [3]. This can also be observed in the present study. The knowledge of each patient's individual kinetic-dynamic approach is important for an optimal treatment. It is also clear that frequent assessments are needed to find an optimal dosing. From a practical point of view, objective assessment tools are required, in order to optimize the treatments. The large variation in the results makes it hard to draw strong, general, conclusions about the relationship between the levodopa plasma concentration and the effect, and a model-based approach for the analysis of the data would be appropriate. With the flexibility that the microtablets provide, the individualization of treatment may become easier, with respect to fine-tuned dosing. Further analysis of the results from this study may give individualized guidance on how to determine what the optimal dose is for a patient based on their response to a test dose.

In summary, the systemic dose-adjusted exposure and maximum concentration of levodopa, in a PD population following administration of levodopa/carbidopa microtablets in fasting state, was found to be higher in patients compared with previously reported values from young healthy volunteers. A high between subject variability with respect to response and duration of effect was observed, highlighting the importance of a continuous and individual assessment of motor function in order to optimize treatment effect. 
Acknowledgements We thank CTC personnel for their professional assistance.

Author roles 1. Research project: A. Conception, B. Organization, C. Execution; 2. Statistical Analysis: A. Design, B. Execution, C. Review and Critique; 3. Manuscript Preparation: A. Writing of the first draft, B. Review and Critique;
Marina Senek:
$1 A, 1 B, 1 C, 2 A, 2 B, 3 A$.
Sten-Magnus Aquilonius:
1. C., 2. C, 3. B
Håkan Askmark:
1. C., 2. C, 3. B
Filip Bergquist:
1. A., 1. B., 1. C., 2. C., 3. B.
Radu Constantinescu:
1. C., 2. C, 3. B
Anders Ericsson:
1. A., 1. B., 2. C., 3. B.
Sara Lycke:
1. A., 1. B., 1. C., 2. C., 3. B
Alexander Medvedev:
1. A., 1B, 2. C., 3. B
Mevludin Memedi:
1. A., 2. C., 3. B.
Fredrik Ohlsson:
1. A., 1. B., 2. C., 3. B.
Jack Spira:
1. A., 1. C., 2. C., 3. B
Jerker Westin:
1. A., 2. C., 3. B.
Dag Nyholm
A., 1. B.,1. C., 2. A., 2. C., 3. B.

\section{Compliance with ethical standards}

Funding This study was funded by Vinnova, Sweden's innovation agency "Innovations for Future Health," and was in collaboration with Uppsala University Hospital, Sahlgrenska University Hospital, Uppsala University, Dalarna University, Acreo Swedish ICT, Cenvigo, and Sensidose AB.

Ethical approval All procedures performed in studies involving human participants were in accordance with the ethical standards of the institutional and/or national research committee and with the 1964 Helsinki declaration and its later amendments or comparable ethical standards.

Conflict of interest Marina Senek reports no disclosures/conflict of interest.

Sten-Magnus Aquilonius is co-founder of Sensidose AB and shareholder.

Håkan Askmark reports no disclosures/conflict of interest.

Dr. Bergquist reports personal fees, non-financial support, and other from Global Kinetics Inc., Australia; non-financial support and other from Sensidose AB, Sweden; grants from Stiftelsen for Strategisk Forskning; grants from Västra Götalandsregionen, ALF Research Agreement during the conduct of the study; personal fees from Abbvie Pharmaceuticals, Italy; personal fees from the National Board of Health and Welfare outside the submitted work.

Radu Constantinescu reports grants from Västra Götalandsregionen, ALF Research Agreement, and from Göteborgs Läkaresällskap (The Göteborg Medical Society). Anders Ericsson is an employee at Acreo that has received grants from Stiftelsen for Strategisk Forskning.

Sara Lycke reports no disclosures/conflict of interest.
Alexander Medvedev reports no disclosures/conflict of interest.

Mevludin Memedi is an employee of Dalarna University and Örebro

University, and a shareholder in Jemardator AB.

Fredrik Ohlsson is an employee at Acreo that has received grants from Stiftelsen for Strategisk Forskning.

Jack Spira is an employee and shareholder of Sensidose AB.

Jerker Westin is employed by Dalarna University and co-founder and shareholder of Jemardator AB.

Dag Nyholm receives royalties from Liber AB; has served as a consultant to Sensidose AB and OrbiMed Advisors LLC; has received honoraria from $\mathrm{H}$. Lundbeck AB, Movement Disorders Society, NordicInfu Care, and The National Board of Health and Welfare; has received lecture fees from AbbVie and NordicInfu Care; has received research support from AbbVie, Ipsen, Selanders Foundation, Swedish Knowledge Foundation, Swedish Parkinson's Disease Foundation, Swedish Research Council, and VINNOVA Sweden's innovation agency; is a co-founder and stock owner in Jemardator AB; receives remuneration from the website netdoktor.se for participation in an expert panel; and has received institutional support from the Uppsala University Hospital.

Open Access This article is distributed under the terms of the Creative Commons Attribution 4.0 International License (http:// creativecommons.org/licenses/by/4.0/), which permits unrestricted use, distribution, and reproduction in any medium, provided you give appropriate credit to the original author(s) and the source, provide a link to the Creative Commons license, and indicate if changes were made.

\section{References}

1. Senek M, Nyholm D (2014) Continuous drug delivery in Parkinson's disease. CNS Drugs 28:19-27

2. Ahlskog JE, Muenter MD (2001) Frequency of levodopa-related dyskinesias and motor fluctuations as estimated from the cumulative literature. Mov Disord Off J Mov Disord Soc. 16:448-458

3. Nyholm D, Johansson A, Aquilonius S-M, Hellquist E, Lennernäs H, Askmark H (2012) Complexity of motor response to different doses of duodenal levodopa infusion in Parkinson disease. Clin Neuropharmacol 35:6-14

4. Marconi R, Lefebvre-Caparros D, Bonnet AM, Vidailhet M, Dubois B, Agid Y (1994) Levodopa-induced dyskinesias in Parkinson's disease phenomenology and pathophysiology. Mov Disord Off J Mov Disord Soc. 9:2-12

5. Westin J, Nyholm D, Pålhagen S et al (2011) A pharmacokineticpharmacodynamic model for duodenal levodopa infusion. Clin Neuropharmacol 34:61-65

6. Nyholm D, Lewander T, Johansson A, Lewitt PA, Lundqvist C, Aquilonius S-M (2008) Enteral levodopa/carbidopa infusion in advanced Parkinson disease: long-term exposure. Clin Neuropharmacol 31:63-73

7. Nyholm D, Odin P, Johansson A et al (2013) Pharmacokinetics of levodopa, carbidopa, and 3-O-methyldopa following 16-hour jejunal infusion of levodopa-carbidopa intestinal gel in advanced Parkinson's disease patients. AAPS J 15:316-323

8. Metman LV, Hoff J, Mouradian MM, Chase TN (1994) Fluctuations in plasma levodopa and motor responses with liquid and tablet levodopa/carbidopa. Mov Disord Off J Mov Disord Soc. 9:463-465

9. Nyholm D, Ehrnebo M, Lewander T et al (2013) Frequent administration of levodopa/carbidopa microtablets vs levodopa/ carbidopa/entacapone in healthy volunteers. Acta Neurol Scand 127:124-132 
10. Bredenberg S, Nyholm D, Aquilonius SM, Nyström C (2003) An automatic dose dispenser for microtablets - a new concept for individual dosage of drugs in tablet form. Int J Pharm 261:137-146

11. Svenningsson P, Rosenblad C, Af Edholm Arvidsson K et al (2015) Eltoprazine counteracts 1-DOPA-induced dyskinesias in Parkinson's disease: a dose-finding study. Brain J Neurol 138:963-973

12. Nyholm D, Lewander T, Gomes-Trolin C et al (2012) Pharmacokinetics of levodopa/carbidopa microtablets versus levodopa/benserazide and levodopa/carbidopa in healthy volunteers. Clin Neuropharmacol 35:111-117

13. Tomlinson CL, Stowe R, Patel S, Rick C, Gray R, Clarke CE (2010) Systematic review of levodopa dose equivalency reporting in Parkinson's disease. Mov Disord Off J Mov Disord Soc. 25: 2649-2653

14. Stacy MA, Murphy JM, Greeley DR, Stewart RM, Murck H, Meng X (2008) The sensitivity and specificity of the 9-item wearing-off questionnaire. Parkinsonism Relat Disord 14:205-212

15. Nyholm D, Nilsson Remahl AIM, Dizdar N et al (2005) Duodenal levodopa infusion monotherapy vs oral polypharmacy in advanced Parkinson disease. Neurology 64:216-223

16. Wesselhoff J, Gauding J. Validering av texten "Trapetskonstnären": analys av högläsning av personer med neuromotorisk talstörning och friska kontrollpersoner. Accessed at: http://openarchive.ki. se/xmlui/handle/10616/44955. Accessed 8 Feb 2016

17. R Core Team (2015) R: A language and environment for statistical computing. R Foundation for Statistical Computing
18. Acharya C, Hooker AC, Yıldız Türkyılmaz G, Jönsson S, Karlsson MO A diagnostic tool for population models using noncompartmental analysis: the ncappc package for R. Comput Methods Prog Biomed

19. Nyholm D, Karlsson E, Lundberg M, Askmark H (2010) Large differences in levodopa dose requirement in Parkinson's disease: men use higher doses than women. Eur J Neurol 17:260-266

20. Thébault JJ, Guillaume M, Levy R (2004) Tolerability, safety, pharmacodynamics, and pharmacokinetics of rasagiline: a potent, selective, and irreversible monoamine oxidase type B inhibitor. Pharmacother J Hum Pharmacol Drug Ther 24: 1295-1305

21. Adamiak U, Kaldonska M, Klodowska-Duda G et al (2010) Pharmacokinetic-pharmacodynamic modeling of levodopa in patients with advanced Parkinson disease. Clin Neuropharmacol 33: 135-141

22. Contin M, Riva R, Martinelli P, Albani F, Baruzzi A (1991) Effect of age on the pharmacokinetics of oral levodopa in patients with Parkinson's disease. Eur J Clin Pharmacol 41:463-466

23. Murata M, Mizusawa H, Yamanouchi H, Kanazawa I (1996) Chronic levodopa therapy enhances dopa absorption: contribution to wearing-off. J Neural Transm Vienna Austria 103: $1177-1185$

24. Robertson DR, Wood ND, Everest $\mathrm{H}$ et al (1989) The effect of age on the pharmacokinetics of levodopa administered alone and in the presence of carbidopa. Br J Clin Pharmacol 28:61-69 